Article

\title{
Pyrrolidinium FSI and TFSI-Based Polymerized Ionic Liquids as Electrolytes for High-Temperature Lithium-Ion Batteries
}

\author{
Manfred Kerner ${ }^{(D)}$ and Patrik Johansson * (D) \\ Department of Physics, Chalmers University of Technology, SE-41296 Gothenburg, Sweden; \\ manfred.kerner@chalmers.se \\ * Correspondence: patrik.johansson@chalmers.se; Tel.: +46-31-772-3178
}

Received: 29 December 2017; Accepted: 1 February 2018; Published: 13 February 2018

\begin{abstract}
Promising electrochemical and dynamical properties, as well as high thermal stability, have been the driving forces behind application of ionic liquids (ILs) and polymerized ionic liquids (PILs) as electrolytes for high-temperature lithium-ion batteries (HT-LIBs). Here, several ternary lithium-salt/IL/PIL electrolytes ( PIL $_{\mathrm{el}}$ ) have been investigated for synergies of having both FSI and TFSI anions present, primarily in terms of physico-chemical properties, for unique application in HT-LIBs operating at $80^{\circ} \mathrm{C}$. All of the electrolytes tested have low $\mathrm{T}_{\mathrm{g}}$ and are thermally stable $\geq 100^{\circ} \mathrm{C}$, and with TFSI as the exclusive anion the electrolytes (set A) have higher thermal stabilities $\geq 125^{\circ} \mathrm{C}$. Ionic conductivities are in the range of $1 \mathrm{mS} / \mathrm{cm}$ at $100{ }^{\circ} \mathrm{C}$ and slightly higher for set A PIL $\mathrm{e}_{\mathrm{e}}$, which, however, have lower oxidation stabilities than set B PIL $\mathrm{el}_{\mathrm{el}}$ with both FSI and TFSI anions present: $3.4-3.7 \mathrm{~V}$ vs. $4.2 \mathrm{~V}$. The evolution of the interfacial resistance increases for all $\mathrm{PIL}_{\mathrm{el}}$ during the first $40 \mathrm{~h}$, but are much lower for set $\mathrm{B} \mathrm{PIL}_{\mathrm{el}}$ and generally decrease with increasing Li-salt content. The higher interfacial resistances only influence the cycling performance at high C-rates $(1 \mathrm{C})$, where set B PILel with high Li-salt content performs better, while the discharge capacities at the $0.1 \mathrm{C}$ rate are comparable. Long-term cycling at $0.5 \mathrm{C}$, however, shows stable discharge capacities for 100 cycles, with the exception of the set B PIL $\mathrm{PL}_{\mathrm{el}}$ with high Li-salt content. Altogether, the presence of both FSI and TFSI anions in the PILel results in lower ionic conductivities and decreased thermal stabilities, but also higher oxidation stabilities and reduced interfacial resistances and, in total, result in an improved rate capability, but compromised long-term capacity retention. Overall, these electrolytes open for novel designs of HT-LIBs.
\end{abstract}

Keywords: poly ionic liquids; poly(DDA); Pyr14; ternary electrolytes; dynamical properties; electrochemical properties

\section{Introduction}

The continuously increasing demand of electrified vehicles leads to increased demands of batteries with high energy densities, in particular lithium-ion batteries (LIBs) [1-3]. Often the electrolytes used in LIBs contain the lithium hexafluorophosphate $\left(\mathrm{LiPF}_{6}\right)$ salt dissolved in different volatile organic solvents which altogether restrict battery usage to temperatures $<60{ }^{\circ} \mathrm{C}[4,5]$. As a result, the LIB in hybrid or fully electric vehicles (xEVs) has its own cooling system, keeping it at a safe but slightly elevated operating temperature-often ca. $30-35^{\circ} \mathrm{C}$. A drastically alternative approach is to remove the special battery cooling system and merge it with the cooling system of the power electronics, working to cool to ca. $80-100{ }^{\circ} \mathrm{C}$, whereby the overall efficiency of the vehicle can be increased [6]. Different concepts have been employed to improve the thermal stability and create high-temperature (HT) stable LIB (HT-LIB) electrolytes. Conventional electrolytes based on designated organic solvents mixed with additives improve safety and thermal stability [7], and inherently low flammable and thermally-stable ionic liquids (ILs) mixed with thermally more stable salts create HT 
stable electrolytes [8]. Other alternatives are hybrid electrolytes [9]—containing both ILs and organic solvents-and polymer electrolytes [10,11]. All of these electrolytes have their own advantages and disadvantages; Polymer electrolytes were demonstrated in the 1980's [12,13] and are applied in the Bolloré Bluecars in Paris Autolib' car-sharing service (and other cities), while no wider application has yet been demonstrated, due to the rather low specific energy density of $100 \mathrm{Wh} / \mathrm{kg}$ when compared to LIBs and the demand of continuous charging when not in use [14]. High ionic conductivities are intrinsically needed to rapidly shuttle lithium ions from one electrode to the other and prevent charge carrier depletion and polarization effects in the electrolyte and, in general, foster excellent battery cycling performance. A common requirement for battery electrolytes is a minimum conductivity of $0.1 \mathrm{mS} / \mathrm{cm}$ at room temperature (RT) [15]. IL based electrolytes $\left(\mathrm{IL}_{\mathrm{el}}\right)$ have high ionic conductivities at room temperature [16], but often rather low $\mathrm{Li}^{+}$transference numbers [17]. Considering that the IL ions contribute inherently to the ionic conductivity, a tougher requirement of $1 \mathrm{mS} / \mathrm{cm}$ at $\mathrm{RT}$ is, therefore, reasonable. The ionic conductivities and $\mathrm{Li}^{+}$transference number of ternary polymerized ionic liquid based electrolytes ( $\left.\mathrm{PIL}_{\mathrm{el}}\right)$ could be positively influenced by the IL-PIL interaction, as for an $\mathrm{IL}_{\mathrm{el}}$ confined in silica monoliths [18].

Polymerized ionic liquids (PILs, also known as poly(ILs)) are, in a way, a combination of an IL and a polymer. During the synthesis, the IL cations or anions are the polymerized monomers and connected covalently to create the backbone of the PIL [19]. The first PIL imidazolium based homopolymer was synthesized in 1973 [20], while the first PIL with an ionic conductivity of $1 \mathrm{mS} / \mathrm{cm}$ at RT was investigated in 1998 [21]. Today, the field of PILs comprises many polycations and polyanions [22]. When a lithium salt is added a PIL $\mathrm{el}_{\mathrm{e}}$ is created [23]. The ionic conductivities of PIL $\mathrm{el}_{\mathrm{e}}$ are quite low compared to $\mathrm{IL}_{\mathrm{el}}$, but can be increased by addition of an IL [23]. This way, ternary electrolytes also referred to as ion gels [19] can be created by various combinations of ILs and PILs. For example, a mixed poly(diallyldimethylammonium) (poly(DDA), also known as poly(DADMA)) PIL and pyrrolidinium IL cation and bis(trifluoromethanesulfonyl)imide (TFSI) anion matrix (Figure 1) doped with LiTFSI salt electrolyte has an ionic conductivity of ca. $10^{-4} \mathrm{~S} / \mathrm{cm}$ at RT [24], a wide electrochemical stability window (up to $5 \mathrm{~V}$ vs. $\mathrm{Li}^{+} / \mathrm{Li}^{\circ}$ ), excellent lithium stripping/plating stability, and a good battery cycling performance, enabling discharge capacities of $140 \mathrm{mAh} / \mathrm{g}$ at $0.2 \mathrm{C}$ for Li I I lithium iron phosphate (LFP) cells at $40{ }^{\circ} \mathrm{C}$ [25]. Another ternary PIL el with the same PIL and Li-salt, but mixed with 1-ethyl-3-methylimidazolium (EMI)-TFSI as the IL, showed discharge capacities of $150 \mathrm{mAh} / \mathrm{g}$ at 0.5 C for a Li I I LFP cell at RT, but the HT performance is unknown [26]. Recently, Wang et al. have shown a PIL $_{\mathrm{el}}$ containing the bis(fluorosulfonyl)imide (FSI) and bis(trifluoromethanesulfonyl)imide (TFSI )anions and $\mathrm{Al}_{2} \mathrm{O}_{3}$ nano-particles, to enable a high (50\%) IL content with an ionic conductivity of $0.3 \mathrm{mS} / \mathrm{cm}$ at $30{ }^{\circ} \mathrm{C}$ and stable polarization of $\mathrm{Li} \mid \mathrm{I}$ Li symmetric cells [27].

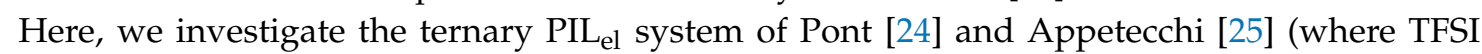
is the only anion present) further by using different compositions of Li-salt/IL/PIL. Additionally, we investigate ternary PIL $_{\mathrm{el}}$ where both FSI and TFSI anions are present, by having LiTFSI in an FSI based IL and PIL, to elucidate any possible synergetic effects, primarily in terms of thermal and dynamic properties. The evolution of the interfacial resistances, the electrochemical stability windows and the battery performance here are all obtained at $80^{\circ} \mathrm{C}$, thus, clearly aiming at HT-LIB application. 


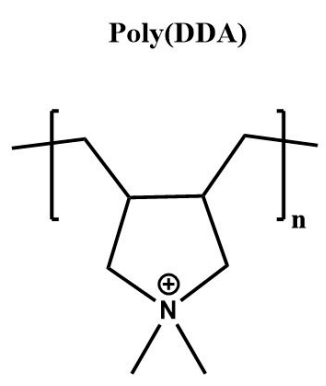

FSI

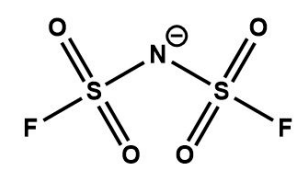

$\mathrm{Pyr}_{14}$

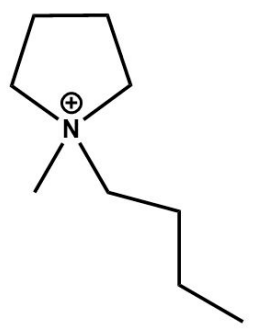

TFSI

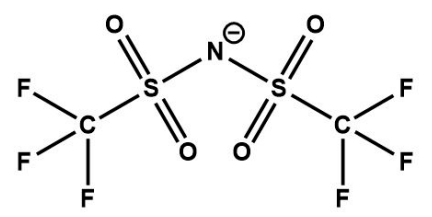

Figure 1. Chemical structures of poly(DDA), Pyr14, FSI and TFSI.

\section{Results and Discussion}

\subsection{Thermal Stability}

The $\mathrm{T}_{\mathrm{g}}$ of the PIL $\mathrm{e}_{\mathrm{el}}$ are independent of the IL/PIL ratio as all the PIL $\mathrm{P}_{\mathrm{el}}$ ("A 2.4:1 to A 3.3:1") investigated by Appetecchi et al. had a $\mathrm{T}_{\mathrm{g}}$ of $-67^{\circ} \mathrm{C}$ [25]. Here, the $\mathrm{T}_{\mathrm{g}}$ increased with increasing lithium salt content from $-81{ }^{\circ} \mathrm{C}$ to $-63{ }^{\circ} \mathrm{C}$ for the PIL $\mathrm{Pl}_{\mathrm{el}}$ with TFSI as the exclusive anion (set $\mathrm{A}$ ) and from $-82{ }^{\circ} \mathrm{C}$ to $-74{ }^{\circ} \mathrm{C}$ for the PILel with both FSI and TFSI anions (set B). The $\mathrm{T}_{\mathrm{g}}$ stayed unchanged from PIL PLl $_{\text {B }}$ 9:1 to B 6:1, which could be due to a minor effect of LiTFSI for set B as the total changes in $\mathrm{T}_{\mathrm{g}}$ overall are much smaller than for set $\mathrm{A}$. The deviation from the results of Appetecchi et al. could be arising from their lower PIL/IL ratio and/or higher lithium salt content.

All of the investigated $\mathrm{PIL}_{\mathrm{el}}$ have low $\mathrm{T}_{\mathrm{g}}$, with the lowest at $-82{ }^{\circ} \mathrm{C}$, due to the low lithium salt contents (Figure 2a and Table 1). The increased $\mathrm{T}_{\mathrm{g}}$ with LiTFSI content is likely due to lithium ion induced bonds with the PIL and/or IL, thus acting as an anti-plasticizer and increasing the overall rigidity of the $\mathrm{PIL}_{\mathrm{el}}$, as e.g., seen for $\mathrm{LiClO}_{4}$ in polycarbonate [28]. The difference in the increase of the $\mathrm{T}_{\mathrm{g}}$ between set $\mathrm{A}$ and $\mathrm{B}$ can be attributed to a lower stabilization by Li-FSI complexes as compared to Li-TFSI complexes, as calculated ab initio for $\mathrm{IL}_{\mathrm{el}}$ [29]. Moving up in temperature, a small endothermic peak appears at ca. $150{ }^{\circ} \mathrm{C}$ for set $\mathrm{B}$, but nothing $\leq 200{ }^{\circ} \mathrm{C}$ for set $\mathrm{A}$. The feature for set $\mathrm{B}$ is most likely not a phase transition, but rather the start of a decomposition process in accordance with the TGA results. The range free of phase transition of the $\mathrm{PIL}_{\mathrm{el}}$ from $\mathrm{T}_{\mathrm{g}}$ to the temperature of confirmed stability (by isothermal TGA) are shown in Figure $2 \mathrm{~b}$ in solid color, while the slightly transparent part of the bars give a hint on the real thermal stability (unconfirmed).

Table 1. Glass transitions, decomposition temperatures, and ionic conductivities at 20 and $80{ }^{\circ} \mathrm{C}$.

\begin{tabular}{ccccc}
\hline Electrolyte & $\mathbf{T}_{\mathbf{g}}\left({ }^{\circ} \mathbf{C}\right)$ & $\mathbf{T}_{\mathbf{d}}\left({ }^{\circ} \mathbf{C}\right)$ & $\boldsymbol{\sigma}_{\mathbf{2 0}}{ }^{\circ} \mathbf{C}(\mathbf{S} / \mathbf{c m})$ & $\boldsymbol{\sigma}_{\mathbf{8 0}}{ }^{\circ} \mathbf{C}(\mathbf{S} / \mathbf{c m})$ \\
\hline A 9:1 & -81 & 349 & $3.3 \times 10^{-5}$ & $6.0 \times 10^{-4}$ \\
A 6:1 & -72 & 352 & $5.0 \times 10^{-5}$ & $1.0 \times 10^{-3}$ \\
A 3:1 & -63 & 352 & $1.9 \times 10^{-4}$ & $1.9 \times 10^{-3}$ \\
B 9:1 & -82 & 174 & $3.8 \times 10^{-5}$ & $4.5 \times 10^{-4}$ \\
B 6:1 & -82 & 193 & $7.7 \times 10^{-5}$ & $7.1 \times 10^{-4}$ \\
B 3:1 & -74 & 188 & $7.4 \times 10^{-5}$ & $1.0 \times 10^{-3}$ \\
\hline
\end{tabular}



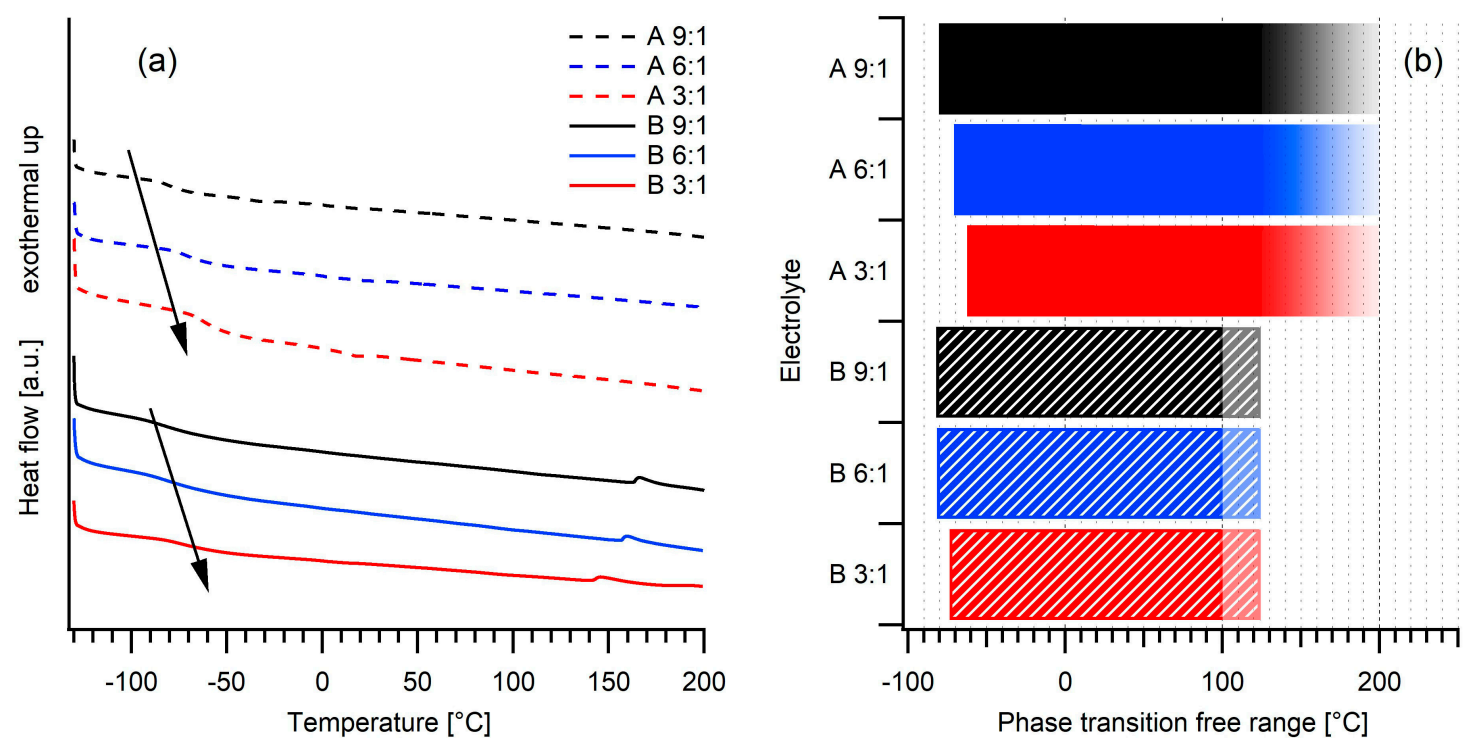

Figure 2. DSC heating traces (a) and phase transition free ranges (b).

The dynamic TGA data show the beginning of a mass loss i.e., $\mathrm{T}_{\mathrm{d}}$ at ca. $170^{\circ} \mathrm{C}$ for set $\mathrm{B}$, ca. $180^{\circ} \mathrm{C}$ earlier than for set $\mathrm{A}$ at $350^{\circ} \mathrm{C}$ (Figure 3a). This difference in thermal stability between FSI and TFSI based systems has previously been observed for EMI cation based $\mathrm{IL}_{\mathrm{el}}$ [8], possibly related to a lower thermal stability of the FSI anion when lithium ions are present. The $\mathrm{T}_{\mathrm{d}}$ of set $\mathrm{A}$ at ca. $350{ }^{\circ} \mathrm{C}$ is lower than for the neat PIL 400-500 ${ }^{\circ} \mathrm{C}$ [24], most likely due to the presence of lithium ions in the electrolyte, which lead to stronger ion-ion interaction in the $\mathrm{PIL}_{\mathrm{el}}$ as seen by the calculated lower interaction energies in $\mathrm{IL}_{\mathrm{el}}$ [29], possibly weakening other bonds in the system. A higher content of lithium salt has previously been shown to further reduce the $\mathrm{T}_{\mathrm{d}}$ to $300^{\circ} \mathrm{C}$ [25]. We, however, did not see any reduction in $T_{d}$ with respect to the lithium salt content increase for set $A$, while in fact a minor improvement was observed for set $\mathrm{B}$. This increased thermal stability is most likely due to the lithium salt itself having a higher $\mathrm{T}_{d}[8]$ than poly $((\mathrm{DDA})(\mathrm{FSI})) / \mathrm{Pyr}_{14} \mathrm{FSI}$. These higher thermal stabilities are rather kinetic effects than inherently thermodynamic, why we performed isothermal TGA for more precise determinations of the $\mathrm{PIL}_{\mathrm{el}}$ thermal stabilities, resulting in no mass loss for set $\mathrm{A}$ at $125{ }^{\circ} \mathrm{C}$, but mass losses between 6.5 and $9.5 \mathrm{wt} \%$ were seen for set $\mathrm{B}$, hence, not truly stable at this temperature.
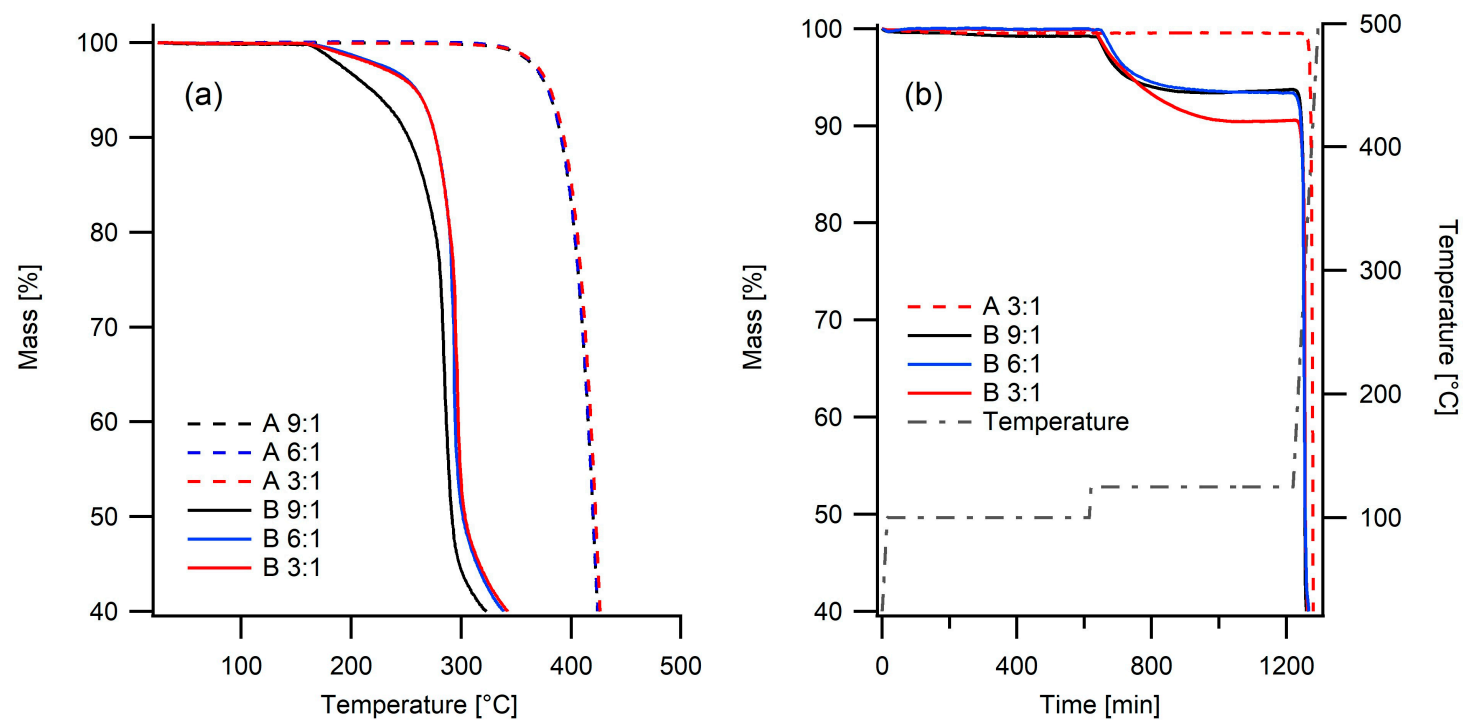

Figure 3. Dynamic (a) and isothermal (b) TGA heating traces of the $\mathrm{PIL}_{\mathrm{el}}$. 


\subsection{Ionic Conductivities}

Over the whole temperature range, the ionic conductivities of set A are roughly the same as for comparable $\mathrm{PIL}_{\mathrm{el}}$ in the literature [25], while there are no comparable data available for set $\mathrm{B}$. At $-50^{\circ} \mathrm{C}$ the ionic conductivity of A 9:1 is $3 \times 10^{-10} \mathrm{~S} / \mathrm{cm}$ (Figure 4) and A 6:1, with $1.5 \mathrm{wt} \%$ more LiTFSI, has an identical ionic conductivity, possibly due to a lower effect of the $\mathrm{Li}^{+}$at lower temperatures combined with an only minor increase in the LiTFSI concentration. Moving to higher temperatures, both $\mathrm{PIL}_{\mathrm{el}}$ show increased ionic conductivities as expected. However, A 6:1 increases more, probably due to an increased amount of charge carriers. The previously mentioned target in ionic conductivity of $1 \mathrm{mS} / \mathrm{cm}$ is obtained for A 6:1 at $80^{\circ} \mathrm{C}$ and for A 9:1 at $100{ }^{\circ} \mathrm{C}$. The PIL $\mathrm{PLl}_{\mathrm{el}}$ with the largest amount of LiTFSI $(8.4 \mathrm{wt} \%$, A 3:1) shows a two magnitudes higher ionic conductivity at $-50^{\circ} \mathrm{C}: 1.2 \times 10^{-8} \mathrm{~S} / \mathrm{cm}$, and while the difference diminishes at higher temperatures $1 \mathrm{mS} / \mathrm{cm}$ is obtained already at $60^{\circ} \mathrm{C}$ and at $120^{\circ} \mathrm{C}$ it has the highest ionic conductivity: $3.6 \mathrm{mS} / \mathrm{cm}$. This points to increased ionic conductivities to mainly result from increased amounts of charge carriers as the dynamics should be lower (higher $\mathrm{T}_{\mathrm{g}}$ ).

Moving on to set $\mathrm{B}$, all $\mathrm{PIL}_{\mathrm{el}}$ have approximately the same ionic conductivities: $1.2-1.8 \times 10^{-8} \mathrm{~S} / \mathrm{cm}$ at $-50{ }^{\circ} \mathrm{C}$ (Figure 4). At $20^{\circ} \mathrm{C}$, the PIL $\mathrm{el}_{\mathrm{el}}$ with the intermediate LiTFSI content (B 6:1) has only a slightly to none higher ionic conductivity than the $\mathrm{PIL}_{\mathrm{el}}$ with the highest content (B 3:1), (Table 1), which at higher temperatures shows the highest ionic conductivity. Overall, the ionic conductivities are lower compared to set $\mathrm{A}$ and only $\mathrm{B} 6: 1$ and $3: 1$ reach $1 \mathrm{mS} / \mathrm{cm}$ at $100{ }^{\circ} \mathrm{C}$ and $80^{\circ} \mathrm{C}$, respectively. This indicates a higher mobility of the $\mathrm{Li}^{+}$(or indeed other ions) in set $\mathrm{A}$, possibly originating in the FSI anions of set $\mathrm{B}$ predominantly creating large complexes of three FSI solvating $\mathrm{Li}^{+}$, rather than two TFSI solvating $\mathrm{Li}^{+}$in set A, as previously found for ILs with exclusively FSI or TFSI present [8]. Another possibility/speculation is that the size of the FSI anion affects more macroscopic material properties.

In summary, both sets show reasonable ionic conductivities at $80^{\circ} \mathrm{C}$, with the largest differences obtained for the PIL $_{\mathrm{el}}$ with the highest and lowest concentrations of LiTFSI, why these were subject to electrochemical studies and long-term cycling at $80^{\circ} \mathrm{C}$.
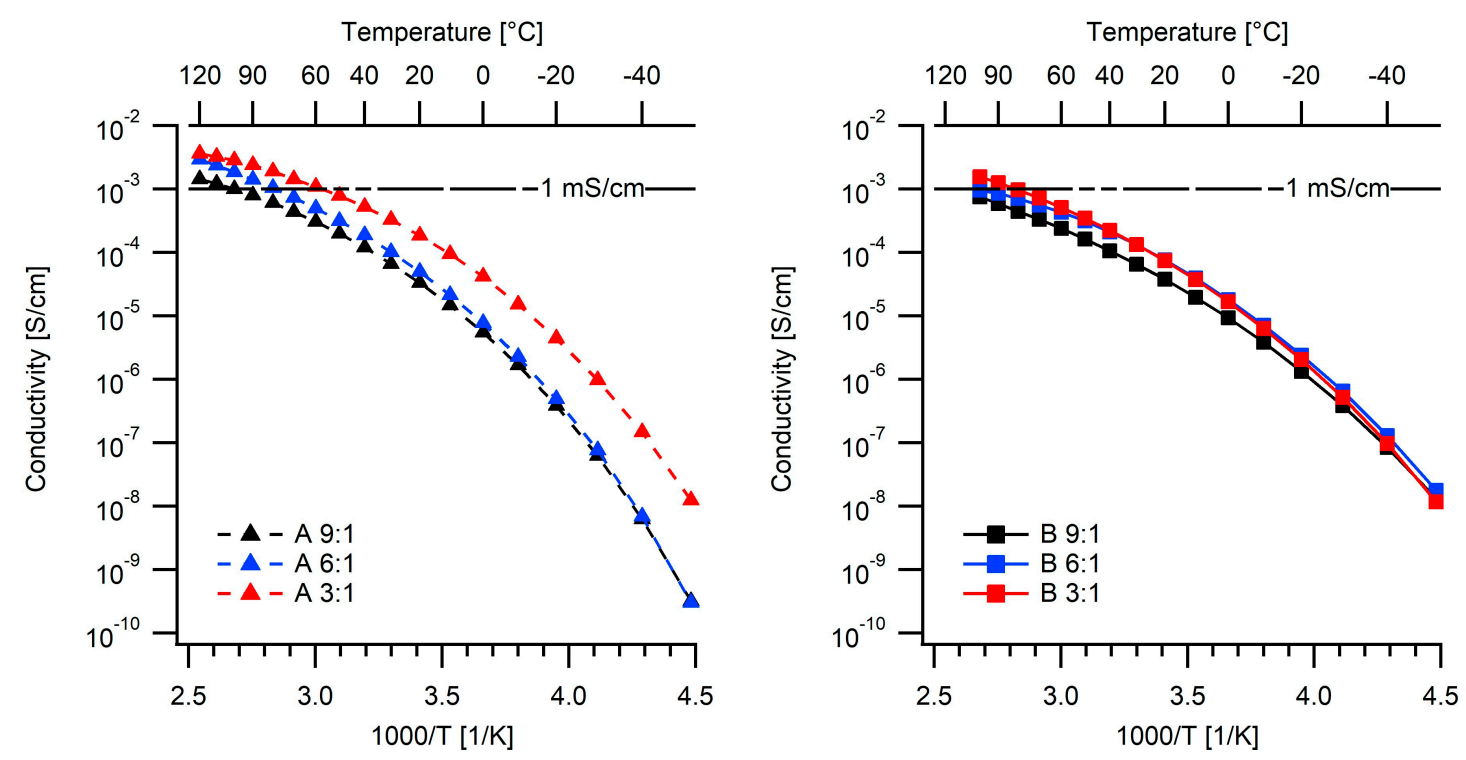

Figure 4. Ionic conductivity cooling traces.

\subsection{Electrochemical Studies}

The LSV scans show small, but distinct, differences between set A and B (Figure 5). For the anodic scans (inset a), set A has current densities starting to increase at ca. $3.4-3.7 \mathrm{~V} \mathrm{vs.} \mathrm{Li}^{+} / \mathrm{Li}^{\circ}$ with a higher stability for A 6:1 and lower for A 9:1, thus, much lower than the $5 \mathrm{~V} \mathrm{vs.} \mathrm{Li}^{+} / \mathrm{Li}^{\circ}$ reported in the literature for comparable $\mathrm{PIL}_{\mathrm{el}}$ [25], possibly originating in the experimental conditions; here $80^{\circ} \mathrm{C}$ 
vs. $20^{\circ} \mathrm{C}$. The lower stability of A 3:1 is likely due to the higher LiTFSI concentration and oxidation of the TFSI anion $[24,30]$. All of set $\mathrm{B}$ has higher oxidation stabilities at ca. $4.2 \mathrm{~V} \mathrm{vs.} \mathrm{Li}^{+} / \mathrm{Li}^{\circ}$, and the current densities increase in a single step, while all of set A show two pre-peaks before increasing critically. The higher stability of set B is either due to a beneficial effect of having both FSI and TFSI anions present or to the lower concentration of the TFSI anion.

Moving to the cathodic scans, all the PIL $\mathrm{el}_{\mathrm{el}}$ follow the same trend. Coming from the OCV, set A increases in current densities at ca. $1.8 \mathrm{~V} \mathrm{vs.} \mathrm{Li}^{+} / \mathrm{Li}^{\circ}$ (inset b, Figure 5), followed by set $\mathrm{B}$ at ca. $1.6 \mathrm{~V}$ vs. $\mathrm{Li}^{+} / \mathrm{Li}^{\circ}$. All PIL $\mathrm{Pl}_{\mathrm{el}}$, show two pre-peaks before the current densities critically increase at a much lower potential of $-0.1 \mathrm{~V} \mathrm{vs.} \mathrm{Li}^{+} / \mathrm{Li}^{\circ}$ which could also arise from lithium plating [31]. The currents at ca. $1.5 \mathrm{~V}$ vs. $\mathrm{Li}^{+} / \mathrm{Li}^{\circ}$ are related to reduction of the TFSI anion and/or the pyrrolidinium cation $[24,30,32]$. Both sets show higher current densities for higher concentrations of LiTFSI, and as the current produced is proportional to the amount of reduced material, this strongly points to TFSI reduction. Altogether, the decreased electrochemical stability of set A stands in contrast to IL based electrolytes, where TFSI based $\mathrm{IL}_{\mathrm{el}}$ are more stable than FSI based $\mathrm{IL}_{\mathrm{el}}[8]$.

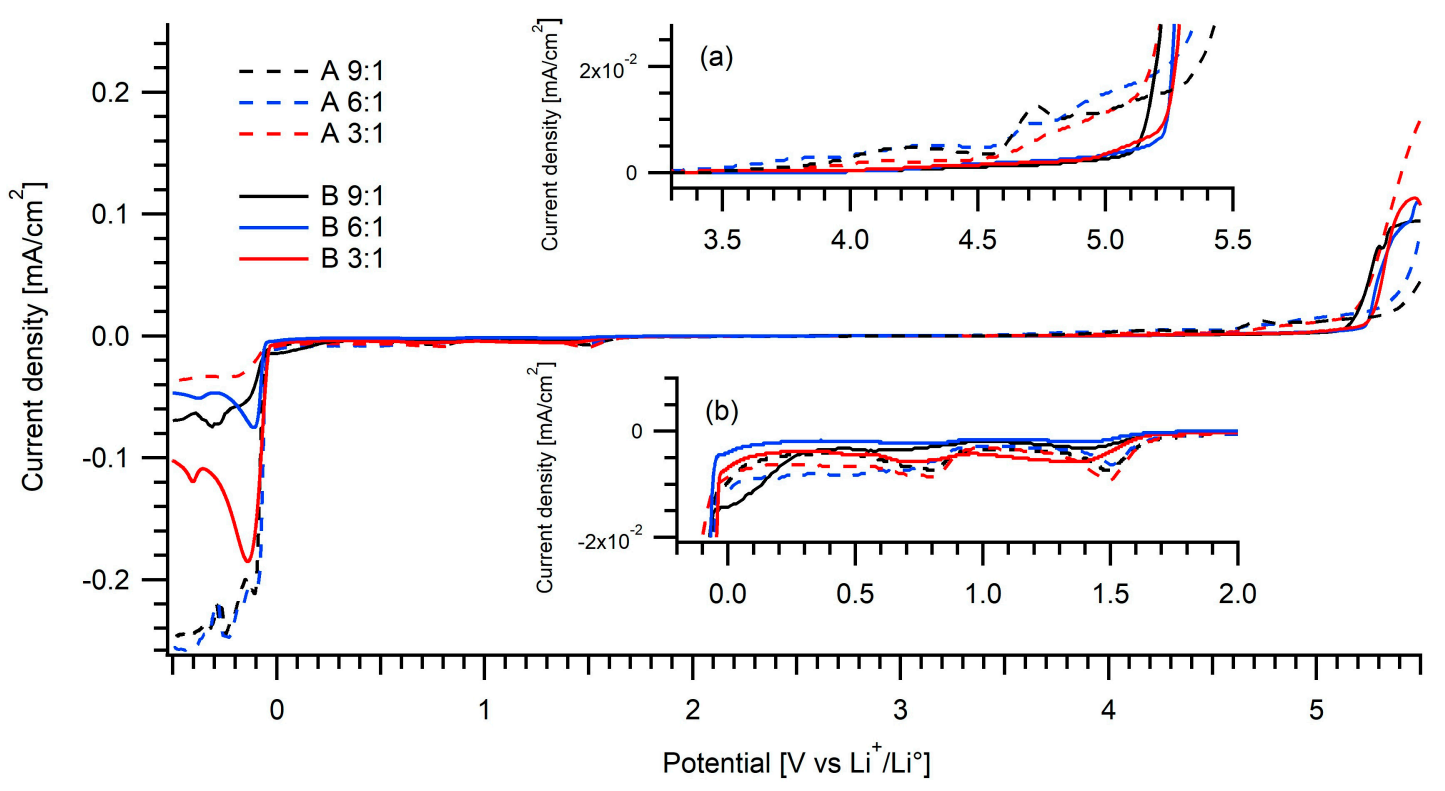

Figure 5. LSV at $1 \mathrm{mV} / \mathrm{s}$ scan rate, with insets for the anodic (a) and cathodic (b) scans.

The evolution of the interfacial resistance at $80^{\circ} \mathrm{C}$ as a function of time was investigated by EIS and found to increase during the first 40 hours and then stabilize (Figure 6a). The plateaus clearly occur at higher resistances for set A, especially for low salt contents: A 9:1 and A 6:1. The interfacial resistance of A 3:1 is in good agreement with the literature, if the temperature difference of $40{ }^{\circ} \mathrm{C}$ is taken into account [25]. A proper lithium salt content can be envisaged as a requirement for film formation and adequate interfacial properties, as an increased LiTFSI concentration reduces the interfacial resistance for both sets with the most dramatic change for set $A$; from ca. $300 \Omega$ to $27 \Omega$. At the same time, the resistance of A 3:1 increases with time, while the resistances of A 6:1, A 9:1, and all of set B remain unchanged (Figure 6b). The plateaus of set B occur at lower interfacial resistances, ranging between 20 and $50 \Omega$, and can, thus, phenomenologically be ascribed to a beneficial effect of the FSI anion. Rate capability tests show clear differences between sets $\mathrm{A}$ and $\mathrm{B}$ and as function of the LiTFSI content at $80^{\circ} \mathrm{C}$ (Figure 7). Starting with set A, the discharge capacity at $0.1 \mathrm{C}$ of ca. $160 \mathrm{mAh} / \mathrm{g}$ is higher than the $144 \mathrm{mAh} / \mathrm{g}$

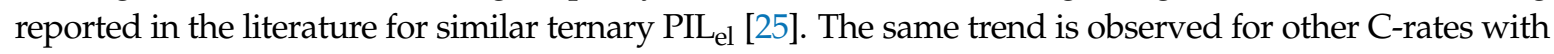
a most dramatic difference for $0.5 \mathrm{C}$, where we observe discharge capacities of ca. $140 \mathrm{mAh} / \mathrm{g}$ while in the literature merely $51 \mathrm{mAh} / \mathrm{g}$ were reported [25]. These differences likely arise from our cycling being performed at $80^{\circ} \mathrm{C}$, as opposed to $40^{\circ} \mathrm{C}$, leading to better dynamics in the material/polymer such as faster segmental motion of the polymer chains, in turn increasing the $\mathrm{Li}^{+}$transference at the electrodes and 
reducing polarization. Differences as function of LiTFSI content is obtained for all C-rates; at low C-rates (0.1-0.5 C), a smaller LiTFSI content results in higher discharge capacities, surprising as A 3:1 showed a higher ionic conductivity at $80^{\circ} \mathrm{C}$ but, at the same time, A 9:1 has lower $\mathrm{T}_{\mathrm{g}}$ and, hence, better dynamics. At $1 \mathrm{C}$ the higher dynamics of A 9:1 is, however, not enough to support high discharge capacities as, most likely, the charge carriers are depleted at the interfaces, while for A 3:1, by virtue of more charge carriers present and its lower interfacial resistance, can support discharge capacities of ca. $35 \mathrm{mAh} / \mathrm{g}$. The capacity retentions when returning to $0.1 \mathrm{C}$ are $99.5 \%$ and $99.9 \%$ for A 9:1 and A 3:1, respectively.
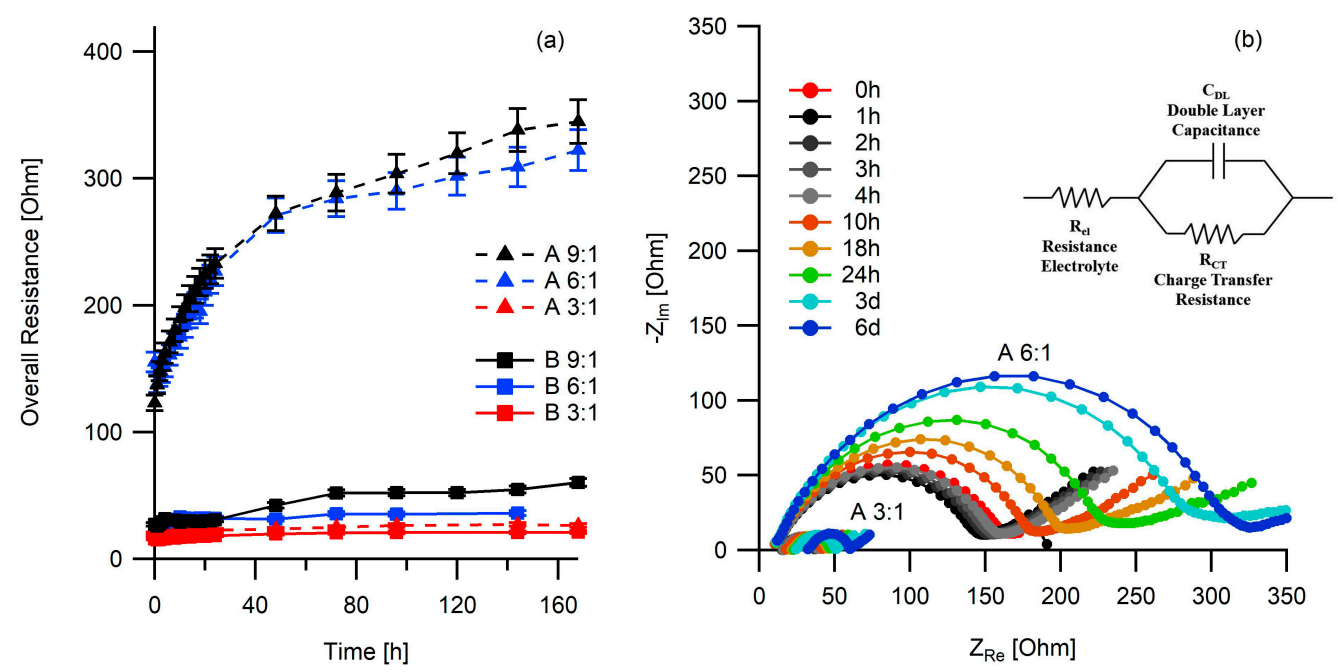

Figure 6. Evolution of the interfacial resistance for Li I I Li symmetrical cells for all $\mathrm{PIL}_{\mathrm{el}}$ (a) and Nyquist plots for A 6:1 and 3:1 (b).

Moving to set $\mathrm{B}$, the trend at low $\mathrm{C}$-rates is opposite compared to set $\mathrm{A}$ (Figure 7). Here, higher discharge capacities are observed for the PIL $\mathrm{el}_{\mathrm{el}}$ with the highest LiTFSI content (B 3:1), likely due to higher ionic conductivities at $80^{\circ} \mathrm{C}$ and only a minor effect of worse dynamics. Therefore, B 3:1 supports discharge capacities of $167 \mathrm{mAh} / \mathrm{g}$ (vs. $159 \mathrm{mAh} / \mathrm{g}$ for B 9:1) at $0.1 \mathrm{C}$, very close to the theoretical $170 \mathrm{mAh} / \mathrm{g}$ [33]. With its large amount of charge carriers, it also supports higher discharge capacities of $49 \mathrm{mAh} / \mathrm{g}$ (vs. 8 $\mathrm{mAh} / \mathrm{g}$ for B 9:1) at $1 \mathrm{C}$. Furthermore, when reducing the C-rate to $0.1 \mathrm{C}$, the capacity retention is $99.4 \%$ (vs. 98.9\% for B 9:1). Altogether, B 3:1 shows the overall best cycling performance of all $\mathrm{PIL}_{\mathrm{el}}$.
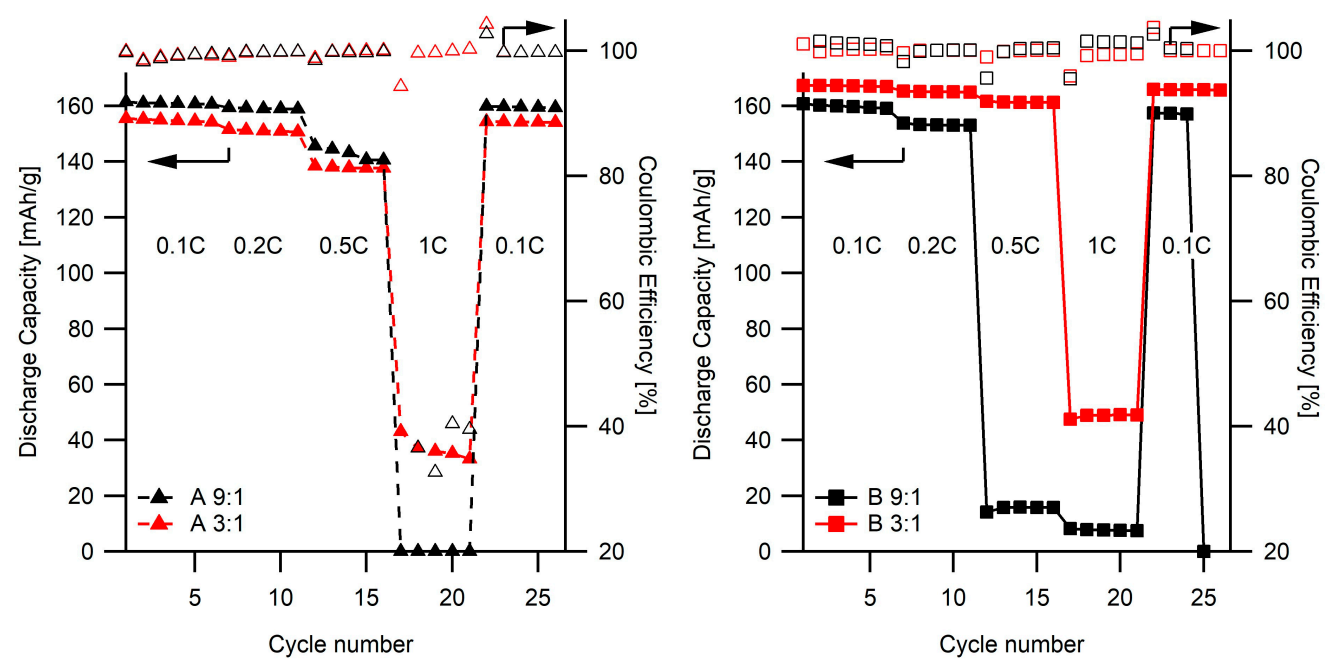

Figure 7. Cycling performance for Li I I LFP cells at varying C-rates. 
Long-term battery cycling for 100 cycles at $0.5 \mathrm{C}$ and $80^{\circ} \mathrm{C}$ show similarities and differences among the PIL (Figure 8). Both PIL el with low LiTFSI content (A 9:1 and B 9:1) exhibit a decrease in discharge capacities for the first five cycles, which also have lower coulombic efficiencies (CE). The discharge capacities and the CE subsequently increase again and stabilize after ca. 40 cycles, delivering stable discharge capacities of ca. $140 \mathrm{mAh} / \mathrm{g}$. This behaviour is likely due to the formation of some kind of solid electrolyte interphase (SEI), [25] which exist also in other polymer based electrolytes [34], but could also be due to improved penetration and contact of the IL component [35] enabling the higher and more stable discharge capacities. The higher CE of A 3:1 vs. A 9:1 and B 3:1 vs. B 9:1 arises from lower interfacial resistances as received from impedance characterization (Figure 6) for the PIL $\mathrm{e}_{\mathrm{el}}$ with higher LiTFSI concentration. Increasing the LiTFSI content shows a beneficial effect for A 3:1, which from the beginning enables the highest discharge capacities among the tested electrolytes, not $B$ 3:1 as for the rate capability tests, possibly due to an improved SEI through the larger concentration of LiTFSI. However, both A 9:1 and B 9:1 reach stable discharge capacities after 40 cycles where discharge capacities of B 9:1 even increased before, possibly due to a beneficial effect of having both FSI and TFSI anions present. The capacity of A 3:1 slightly but continuously decreases, resulting in a capacity retention of $94 \%$ after 100 cycles (the slight fluctuations arise from cables and connections being sensitive to mechanical disturbances). B 3:1 exhibits decreased capacities for the first 25 cycles, likely due to the evolution of an SEI. The absence of this feature during the rate capability test could, admittedly a bit speculative, arise from a milder evolution of the SEI during low C-rate cycling. This is followed by a slight increase and stable plateau before discharge capacities decrease again. After the formation of an SEI, a stable plateau is reached (after 30 cycles) which is followed by a second decrease in discharge capacities, possibly arising from side reactions of the PIL $_{\mathrm{el}}$ induced by the larger LiTFSI content or an unstable SEI, causing further decomposition of the electrolyte.
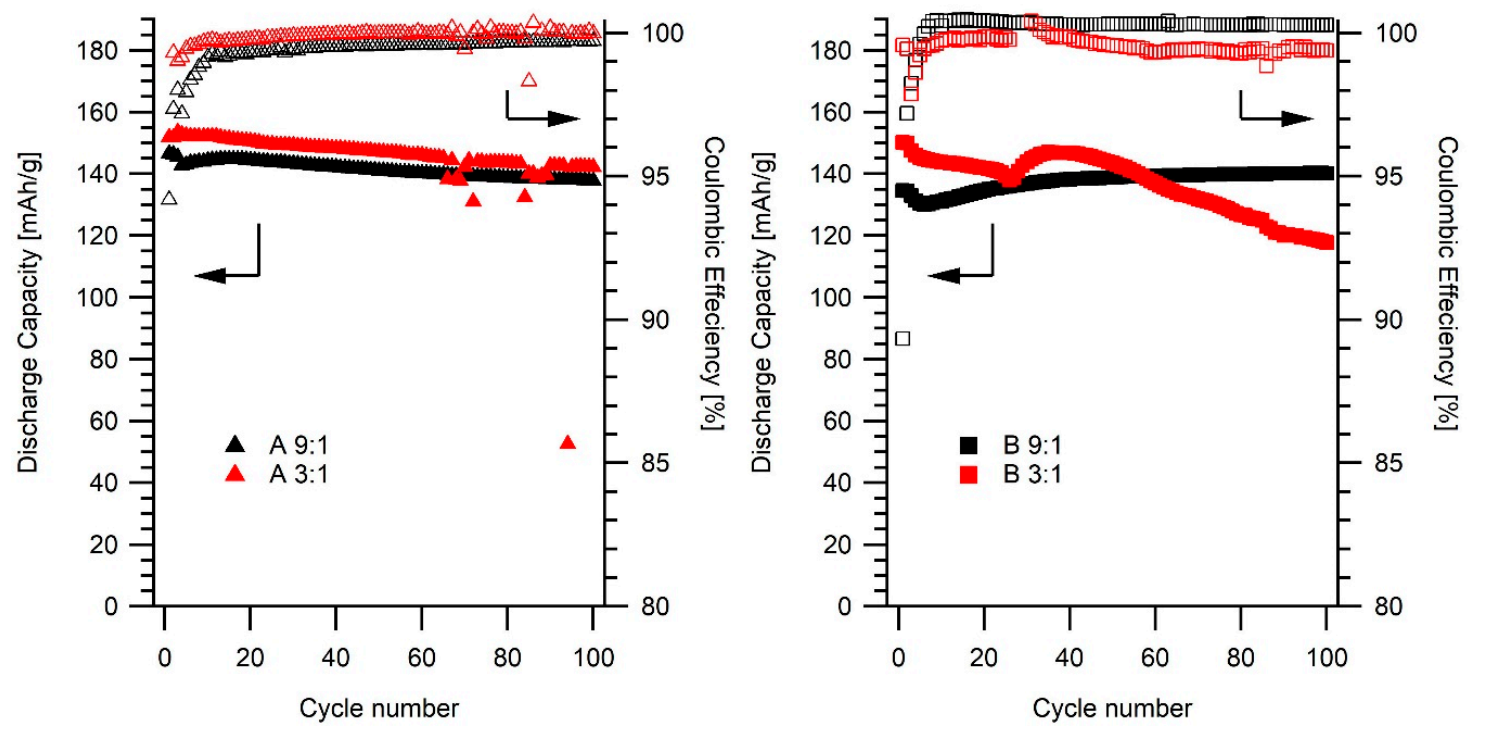

Figure 8. Cycling performance for Li I I LFP cells for 100 cycles at $0.5 \mathrm{C}$ and $80^{\circ} \mathrm{C}$.

\section{Materials and Methods}

\subsection{Materials}

Two PIL (both 99.9\%) were purchased from Solvionic (Toulouse, France) and used as received: (LiTFSI:Pyr ${ }_{14}$ TFSI:Poly((DDA)(TFSI)) and LiTFSI:PYR ${ }_{14}$ FSI:Poly((DDA)(FSI)), both in acetone with a MW: $200,000-350,000$ of the PILs. LiTFSI $(99.9 \%$, Solvionic) was dried under vacuum $(<7 \mathrm{~Pa})$ for $72 \mathrm{~h}$ at $120{ }^{\circ} \mathrm{C}$. Appropriate amounts of LiTFSI were then added to the two PILel $_{\mathrm{el}}$ to alter the original molar fraction of IL to Li-salt from 9:1 to 6:1 and 3:1 for both electrolyte systems. This was 
accompanied by dilution by acetone (99.8\%, Acros Organics, Geel, Belgium), homogenization by magnetic-stirring overnight, and pouring the liquid into Teflon molds for casting. After acetone evaporation, opaque/transparent PIL $_{\mathrm{el}}$ films were obtained (Figure 9) from the samples, and most often disks of different diameters were punched out. Dependent on the IL to LiTFSI molar ratio (9:1, 6:1 or 3:1) and TFSI being the only anion present (set A) or FSI also present (set B), the electrolytes were named accordingly (Table 2).

Table 2. Compositions of the electrolytes.

\begin{tabular}{ccccccc}
\hline & & A & \multicolumn{7}{c}{ B } \\
\hline & $\mathbf{9}$ & $\mathbf{6}$ & \multicolumn{1}{c}{ IL $_{\text {IL }}$ LiTFSI } \\
\hline & $\mathbf{6 : 1}$ & $\mathbf{3 : 1}$ & $\mathbf{9 : 1}$ & $\mathbf{6 : 1}$ & $\mathbf{3 : 1}$ \\
\hline LiTFSI & 2.9 & 4.4 & 8.4 & 3.8 & 5.6 & 10.5 \\
Pyr14TFSI & 39.1 & 38.5 & 36.9 & - & - & - \\
Pyr14FSI & - & - & - & 38.2 & 37.5 & 35.5 \\
Poly(DDA)TFSI & 58.0 & 57.2 & 54.8 & - & - & - \\
Poly(DDA)FSI & - & - & - & 58.0 & 56.9 & 53.9 \\
Name & A 9:1 & A 6:1 & A 3:1 & B 9:1 & B 6:1 & B 3:1 \\
\hline
\end{tabular}

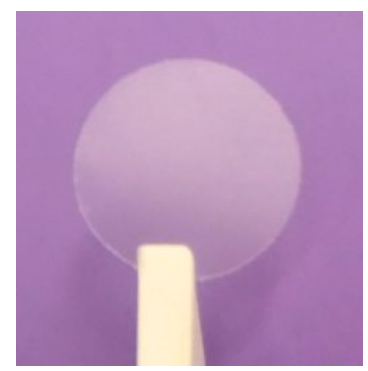

Figure 9. A typical $\mathrm{PIL}_{\mathrm{el}}$ film.

\subsection{Methods}

A Q1000 from TA instruments (New Castle, DE, USA) was used for differential scanning calorimetry (DSC). Approximately $10 \mathrm{mg}$ of sample, hermetically sealed in an aluminum pan, was heated to $100{ }^{\circ} \mathrm{C}\left(80{ }^{\circ} \mathrm{C}\right.$ for set $\mathrm{B}$ ) before cooling to $-130{ }^{\circ} \mathrm{C}$ and re-heated to $200{ }^{\circ} \mathrm{C}$ with $5{ }^{\circ} \mathrm{C} / \mathrm{min}$ cooling/heating rates. Five-minute equilibration intervals were applied at the extreme temperatures. The point of inflection was used to determine the glass transition temperature $\left(\mathrm{T}_{\mathrm{g}}\right)$.

Thermal gravimetric analysis (TGA) was performed using a TG 209 F1 Iris from Netzsch (Selb, Germany). Ca. $10 \mathrm{mg}$ of sample was filled into an aluminum crucible and placed in the sample compartment. A nitrogen flow of $100 \mathrm{~mL} / \mathrm{min}$ was used as purge gas. Each sample was heated from room temperature to $500{ }^{\circ} \mathrm{C}$ at a rate of $5{ }^{\circ} \mathrm{C} / \mathrm{min}$. The decomposition temperatures $\left(\mathrm{T}_{\mathrm{d}}\right)$ were defined as the temperatures of $1 \%$ mass loss. "Long-term" thermal stabilities were studied by $10 \mathrm{~h}$ isothermal treatments at $100{ }^{\circ} \mathrm{C}$ and $125^{\circ} \mathrm{C}$.

Ionic conductivities $(\sigma)$ were obtained from the plateaus of the frequency dependent alternating current (AC) conductivity plots based on dielectric spectroscopy data in the frequency range $0.1 \mathrm{~Hz}$ to $10 \mathrm{MHz}$. A concept 80 broadband dielectric spectrometer from Novocontrol (Montabaur, Germany) with a Quattro Cryosystem temperature control unit was used. The PIL $\mathrm{el}_{\mathrm{el}}(\varnothing=16 \mathrm{~mm})$ discs were placed between two stainless steel discs in a coin cell assembly. Spectra were recorded from $20^{\circ} \mathrm{C}$ to $-30{ }^{\circ} \mathrm{C}$ to $120^{\circ} \mathrm{C}\left(100{ }^{\circ} \mathrm{C}\right.$ for set $\left.\mathrm{B}\right)$ and finally down to $-50{ }^{\circ} \mathrm{C}$ in a sequence of $10^{\circ} \mathrm{C}$ steps. Before each recording the samples were equilibrated for at least $30 \mathrm{~min}$ at each temperature. 
An Ivium- $n$-Stat battery tester from Ivium Technology (Eindhoven, The Netherlands) was used to study the lithium metal/PIL $\mathrm{PLl}_{\mathrm{el}}$ interface evolution at $80^{\circ} \mathrm{C}$ by electrochemical impedance spectroscopy (EIS). A $10 \mathrm{mV}$ AC amplitude was applied in the frequency range of $0.1 \mathrm{~Hz}$ to $200 \mathrm{kHz}$ on $\mathrm{Li}\left|\mathrm{PIL}_{\mathrm{el}}\right| \mathrm{Li}$ symmetric coin cells (Li-foils, $d=200 \mu \mathrm{m}, \varnothing=10 \mathrm{~mm}$; PIL $\mathrm{e}_{\mathrm{el}}, \mathrm{d}=90-150 \mu \mathrm{m}, \varnothing=12.5 \mathrm{~mm}$ ). Spectra were taken at $0,1,2,3$, and $4 \mathrm{~h}$, before starting $2 \mathrm{~h}$ intervals for the first $24 \mathrm{~h}$ and subsequently $24 \mathrm{~h}$ intervals for another six days. The Nyquist plots were fitted and analysed using the non-linear least square fitting program "Boukamp" $[36,37]$ to obtain the interfacial resistances.

Linear sweep voltammetry (LSV) was performed to study the electrochemical stability windows of the PIL $\mathrm{PI}_{\mathrm{el}}$ using two Li I PIL I I stainless steel coin cells for each choice of PIL $_{\mathrm{el}}$. The potential was swept from open circuit voltage (OCV) to $5.5 \mathrm{~V} \mathrm{vs.} \mathrm{Li}^{+} / \mathrm{Li}^{\circ}$ and to $-0.5 \mathrm{~V} \mathrm{vs.} \mathrm{Li}^{+} / \mathrm{Li}^{\circ}$, respectively, at rates of $1 \mathrm{mV} / \mathrm{s}$.

A 580 battery cycler from Scribner Associates Inc. (Southern Pines, NC, USA) was used for the rate capability tests of the $\mathrm{Li}\left|\mathrm{PIL}_{\mathrm{el}}\right| \mathrm{LFP}$ half-cells by galvanostatic charge/discharge between 2.5 and $4.2 \mathrm{~V} \mathrm{vs}$. $\mathrm{Li}^{+} / \mathrm{Li}^{\circ}$ at $0.1-1 \mathrm{C}$ rate for 25 cycles. LFP electrodes, $\varnothing=10 \mathrm{~mm}$ and a loading of $2-3 \mathrm{mg} / \mathrm{cm}^{2}$, were made using the method reported by Kim et al. [38]. Additionally, "long-term" cycling tests were performed for 100 cycles with a $0.5 \mathrm{C}$ rate using the same potential window.

\section{Conclusions}

All PIL $_{\mathrm{el}}$ have low $\mathrm{T}_{\mathrm{g}}$ between -63 and $-82{ }^{\circ} \mathrm{C}$, which increase with the addition of LiTFSI. The increase is more profound for set $\mathrm{A}$, likely due to stronger interactions of $\mathrm{Li}^{+}$with TFSI than with FSI. No other features appeared in the DSC heat traces, with the exception of a small peak for set $\mathrm{B}$ likely due to electrolyte decomposition. Hence, all $\mathrm{PIL}_{\mathrm{el}}$ have wide phase transition-free ranges. Furthermore, all PIL $\mathrm{el}_{\mathrm{el}}$ exhibit high thermal stabilities: $\geq 100^{\circ} \mathrm{C}$, with set A being slightly more stable: $\geq 125^{\circ} \mathrm{C}$ due to the absence of FSI anions. Set $\mathrm{A}$ also has higher ionic conductivities, but also B 6:1 and B 3:1 reach $1 \mathrm{mS} / \mathrm{cm}$ at $100{ }^{\circ} \mathrm{C}$ and $80^{\circ} \mathrm{C}$, respectively. The overall lower ionic conductivities of set $\mathrm{B}$ possibly arise through a different solvation of $\mathrm{Li}^{+}$where also the FSI anion is involved, why further spectroscopic and $\mathrm{Li}^{+}$transference number investigations could be useful. The oxidation stabilities are lower for set A due to the decomposition of TFSI anion at lower potentials (3.4-3.7 V vs. 4.2 V) and its higher concentration of TFSI. The reduction stabilities are similar for all the tested electrolytes. The interfacial resistances increase during the first $40 \mathrm{~h}$ due to the creation of an SEI and are in general much larger for set A, while increasing the LiTFSI concentration lowers them. Rate capability tests show stable cycling performance at low C-rates $(0.1 \mathrm{C}$ and $0.2 \mathrm{C})$ and decreased discharge capacities at $1 \mathrm{C}$, likely due to charge carrier depletion at the interfaces. The long-term cycling performance is best for the PILel with high LiTFSI concentration, A 3:1, with the from the beginning largest stable discharge capacities, while the other $\mathrm{PIL}_{\mathrm{el}}$ need at least 20 cycles to reach a stable plateau.

Acknowledgments: The authors gratefully acknowledge the financial support provided by the Swedish Foundation for Strategic Research (SSF). The authors thank Du-Hyun Lim for the synthesis and supply of LFP electrodes and Marco Agostini for his help with the Boukamp fitting. PJ acknowledges the continuous support from several of Chalmers Areas of Advance: Materials Science, Energy, and Transport.

Author Contributions: M.K. and P.J. conceived and designed the experiments; M.K. performed the experiments; M.K. and P.J. analyzed the data; and M.K. and P.J. wrote the paper.

Conflicts of Interest: The authors declare no conflict of interest. The founding sponsors had no role in the design of the study; in the collection, analyses, or interpretation of data; in the writing of the manuscript; or in the decision to publish the results.

\section{References}

1. Blomgren, G.E. The Development and Future of Lithium Ion Batteries. J. Electrochem. Soc. 2017, 164, A5019-A5025. [CrossRef]

2. Tarascon, J.M.; Armand, M. Issues and challenges facing rechargeable lithium batteries. Nature 2001, 414, 359-367. [CrossRef] [PubMed] 
3. Scrosati, B.; Garche, J. Lithium batteries: Status, prospects and future. J. Power Sources 2010, 195, $2419-2430$. [CrossRef]

4. Sloop, S.E.; Pugh, J.K.; Wang, S.; Kerr, J.B.; Kinoshita, K. Chemical Reactivity of $\mathrm{PF}_{5}$ and $\mathrm{LiPF}_{6}$ in Ethylene Carbonate/Dimethyl Carbonate Solutions. Electrochem. Solid-State Lett. 2001, 4, A42-A44. [CrossRef]

5. Andersson, A.M.; Edstroöm, K. Chemical Composition and Morphology of the Elevated Temperature SEI on Graphite. J. Electrochem. Soc. 2001, 148, A1100-A1109. [CrossRef]

6. Lang, G.; Kitanoski, F.; Kussmann, C. Principal Aspects and Simulation of a Hybrid Demonstrator Vehicle's Cooling System. SAE Tech. Pap. 2007, 1-3483. [CrossRef]

7. Santee, S.; Xiao, A.; Yang, L.; Gnanaraj, J.; Lucht, B.L. Effect of combinations of additives on the performance of lithium ion batteries. J. Power Sources 2009, 194, 1053-1060. [CrossRef]

8. Kerner, M.; Plylahan, N.; Scheers, J.; Johansson, P. Ionic liquid based lithium battery electrolytes: Fundamental benefits of utilising both TFSI and FSI anions? Phys. Chem. Chem. Phys. 2015, 17, 19569-19581. [CrossRef] [PubMed]

9. Plylahan, N.; Kerner, M.; Lim, D.-H.; Matic, A.; Johansson, P. Ionic liquid and hybrid ionic liquid/organic electrolytes for high temperature lithium-ion battery application. Electrochim. Acta 2016, 216, 24-34. [CrossRef]

10. Bergman, M.; Bergfelt, A.; Sun, B.; Bowden, T.; Brandell, D.; Johansson, P. Graft copolymer electrolytes for high temperature Li-battery applications, using poly(methyl methacrylate) grafted poly(ethylene glycol)methyl ether methacrylate and lithium bis(trifluoromethanesulfonimide). Electrochim. Acta 2015, 175, 96-103. [CrossRef]

11. Stephan, A.M.; Nahm, K.S. Review on composite polymer electrolytes for lithium batteries. Polymer (Guildf) 2006, 47, 5952-5964. [CrossRef]

12. Armand, M. Polymers with Ionic Conductivity. Adv. Mater. 1990, 2, 278-286. [CrossRef]

13. Kelly, I.E.; Owen, J.R.; Steele, B.C.H. Poly(ethylene oxide) electrolytes for operation at near room temperature. J. Power Sources 1985, 14, 13-21. [CrossRef]

14. Bolloré, Electric Vehicles, Solutions, 2017. Available online: http://www.bollore.com/en-us/activities/ electricity-storage-and-solutions/electric-vehicles-solutions (accessed on 27 October 2017).

15. Goodenough, J.B.; Kim, Y. Challenges for Rechargeable Li Batteries. Chem. Mater. 2010, 22, 587-603. [CrossRef]

16. Osada, I.; de Vries, H.; Scrosati, B.; Passerini, S. Ionic-Liquid-Based Polymer Electrolytes for Battery Applications. Angew. Chem. Int. Ed. 2016, 55, 500-513. [CrossRef] [PubMed]

17. Frömling, T.; Kunze, M.; Schönhoff, M.; Sundermeyer, J.; Roling, B. Enhanced lithium transference numbers in ionic liquid electrolytes. J. Phys. Chem. B 2008, 112, 12985-12990. [CrossRef] [PubMed]

18. Guyomard-Lack, A.; Said, B.; Dupré, N.; Galarneau, A.; Le Bideau, J. Enhancement of lithium transport by controlling the mesoporosity of silica monoliths filled by ionic liquids. New J. Chem. 2016, 40, 4269-4276. [CrossRef]

19. Shaplov, A.S.; Marcilla, R.; Mecerreyes, D. Recent Advances in Innovative Polymer Electrolytes based on Poly(ionic liquid)s. Electrochim. Acta 2015, 175, 18-34. [CrossRef]

20. Salamone, J.C.; Israel, S.C.; Taylor, P.; Snidert, B. Synthesis and homopolymerization studies of vinylimidazolium salts. Polymer (Guildf) 1973, 14, 639-644. [CrossRef]

21. Watanabe, M.; Yamada, S.-I.; Sanui, K.; Ogata, N. High ionic conductivity of new polymer electrolytes consisting of polypyridinium, pyridinium and aluminium chloride. J. Chem. Soc. Chem. Commun. 1993, 929. [CrossRef]

22. Shaplov, A.S.; Vlasov, P.S.; Lozinskaya, E.I.; Ponkratov, D.O.; Malyshkina, I.A.; Vidal, F.; Okatova, O.V.; Pavlov, G.M.; Wandrey, C.; Bhide, A.; et al. Polymeric ionic liquids: Comparison of polycations and polyanions. Macromolecules 2011, 44, 9792-9803. [CrossRef]

23. Mecerreyes, D. Polymeric ionic liquids: Broadening the properties and applications of polyelectrolytes. Prog. Polym. Sci. 2011, 36, 1629-1648. [CrossRef]

24. Pont, A.-L.; Marcilla, R.; de Meatza, I.; Grande, H.; Mecerreyes, D. Pyrrolidinium-based polymeric ionic liquids as mechanically and electrochemically stable polymer electrolytes. J. Power Sources 2009, 188, 558-563. [CrossRef] 
25. Appetecchi, G.B.; Kim, G.T.; Montanino, M.; Carewska, M.; Marcilla, R.; Mecerreyes, D.; De Meatza, I. Ternary polymer electrolytes containing pyrrolidinium-based polymeric ionic liquids for lithium batteries. J. Power Sources 2010, 195, 3668-3675. [CrossRef]

26. Safa, M.; Chamaani, A.; Chawla, N.; El-Zahab, B. Polymeric Ionic Liquid Gel Electrolyte for Room Temperature Lithium Battery Applications. Electrochim. Acta 2016, 213, 587-593. [CrossRef]

27. Wang, X.; Zhu, H.; Girard, G.M.A.; Yunis, R.; MacFarlane, D.R.; Mecerreyes, D.; Bhattacharyya, A.J.; Howletta, P.C.; Forsyth, M. Preparation and characterization of gel polymer electrolytes using poly(ionic liquids) and high lithium salt concentration ionic liquids. J. Mater. Chem. A 2017, 5, 23844-23852. [CrossRef]

28. Sako, T.; Miyagawa, A.; Yamaguchi, M. Modulus enhancement of polycarbonate by addition of lithium perchlorate. J. Appl. Polym. Sci. 2017, 134, 1-5. [CrossRef]

29. Tsuzuki, S.; Hayamizu, K.; Seki, S. Origin of the Low-Viscosity of [emim] $\left[\left(\mathrm{FSO}_{2}\right)_{2} \mathrm{~N}\right]$ Ionic Liquid and Its Lithium Salt Mixture: Experimental and Theoretical Study of Self-Diffusion Coefficients, Conductivities, and Intermolecular Interactions. J. Phys. Chem. B 2010, 114, 16329-16336. [CrossRef] [PubMed]

30. Shin, J.H.; Henderson, W.A.; Appetecchi, G.B.; Alessandrini, F.; Passerini, S. Recent developments in the ENEA lithium metal battery project. Electrochim. Acta 2005, 50, 3859-3865. [CrossRef]

31. Kühnel, R.-S.; Böckenfeld, N.; Passerini, S.; Winter, M.; Balducci, A. Mixtures of ionic liquid and organic carbonate as electrolyte with improved safety and performance for rechargeable lithium batteries. Electrochim. Acta 2011, 56, 4092-4099. [CrossRef]

32. Agostini, M.; Ulissi, U.; di Lecce, D.; Ahiara, Y.; Ito, S.; Hassoun, J. A Lithium-Ion Battery based on an Ionic Liquid Electrolyte, Tin-Carbon Nanostructured Anode, and $\mathrm{Li}_{2} \mathrm{O}-\mathrm{ZrO}_{2}-\mathrm{Coated} \mathrm{Li}\left[\mathrm{Ni}_{0.8} \mathrm{Co}_{0.15} \mathrm{Al}_{0.05}\right]_{2}$ Cathode. Energy Technol. 2015, 3, 632-637. [CrossRef]

33. Yamada, A.; Chung, S.C.; Hinokuma, K. Optimized $\mathrm{LiFePO}_{4}$ for Lithium Battery Cathodes. J. Electrochem. Soc. 2001, 148, A224. [CrossRef]

34. Xu, C.; Sun, B.; Gustafsson, T.; Edström, K.; Brandell, D.; Hahlin, M. Interface layer formation in solid polymer electrolyte lithium batteries: An XPS study. J. Mater. Chem. A 2014, 2, 7256-7264. [CrossRef]

35. Li, M.; Yang, B.; Wang, L.; Zhang, Y.; Zhang, Z.; Fang, S.; Zhang, Z. New polymerized ionic liquid (PIL) gel electrolyte membranes based on tetraalkylammonium cations for lithium ion batteries. J. Memb. Sci. 2013, 447, 222-227. [CrossRef]

36. Boukamp, B.A. A package for impedance/admittance data analysis. Solid State Ion. 1986, 18-19, $136-140$. [CrossRef]

37. Boukamp, B.A. A nonlinear least squares fit procedure for analysis of immittancs data of electrochemical systems. Solid State Ion. 1986, 20, 31-44. [CrossRef]

38. Kim, J.K.; Choi, J.W.; Cheruvally, G.; Kim, J.U.; Ahn, J.H.; Cho, G.B.; Kim, K.-W.; Ahn, H.-J. A modified mechanical activation synthesis for carbon-coated $\mathrm{LiFePO}_{4}$ cathode in lithium batteries. Mater. Lett. 2007, 61, 3822-3825. [CrossRef]

(C) 2018 by the authors. Licensee MDPI, Basel, Switzerland. This article is an open access article distributed under the terms and conditions of the Creative Commons Attribution (CC BY) license (http:/ / creativecommons.org/licenses/by/4.0/). 